\title{
HLA-mismatched GPBSC infusion therapy in refractory Epstein-Barr virus-associated hemophagocytic lymphohistiocytosis: an observational study from a single center
}

Yue Song, Jingshi Wang, Yini Wang and Zhao Wang ${ }^{*}$

\begin{abstract}
Background: Hemophagocytic lymphohistiocytosis $(H L H)$ is a severe or even fatal inflammatory state. Epstein-Barr virus (EBV) infection-associated HLH (EBV-HLH) is one of the most common secondary HLH and suffers a very poor prognosis. Allo-HSCT is often required for refractory EBV-HLH, but some patients still cannot proceed to the next allo-HSCT due to various factors. This study aimed to observe the efficacy of HLA-mismatched granulocyte colonystimulating factor (G-CSF)-mobilized peripheral blood stem cells (GPBSCs) infusion for refractory EBV-HLH.

Methods: A retrospective case-control study of refractory EBV-HLH patients with GPBSC infusion from HLAmismatched donors after chemotherapy (as GPBSC group) and sole chemotherapy (as control group) was performed. Efficacy was evaluated 2 and 4 weeks and all patients were followed-up until March 1, 2018.

Results: There were 18 cases who accepted infusion between March 2016 and Sep 2017 and 19 were randomly selected from refractory EBV-HLH patients who underwent salvage therapy during the same period for the control group. In GPBSC group, WBC $(p=0.017)$, Fbg $(p=0.040)$, and ferritin $(p=0.039)$ improved significantly after treatment. The overall response rate was $66.7 \%$ (CR 22.2\%, PR 44.4\%). However, there are no significant differences in changes of WBC, HGB, PLT, TG, Fbg, Ferritin, AST, ALT, and T-bil between two groups. Only the Fbg level was recovered better in the GPBSC infusion group $(p=0.003)$. In the GPBSC group, EBV-DNA decreased significantly after 2 weeks $(p=0.001)$ and 4 weeks $(p=0.012)$ after treatment, and the effect of the decrease was significantly better than that of the chemotherapy alone group in 2 weeks but not 4 weeks $(p 2 w=0.011, p 4 w=0.145)$. The median survival time in the infusion group was 20.4 weeks [95\% Cl 10.9, 29.9], and the median survival time in the control group was 10.8 weeks [95\% Cl 0-24.34]. In the short-term, the infusion group's survival rate was better (2-month $88.89 \%$ vs. $52.63 \%, p=0.008$; 3 -month $83.33 \%$ vs. $47.09 \%, p=0.012$ ), but there was no difference in OS ( $p=0.287$ ).

Conclusions: Infusing GPBSCs combined with chemotherapy is effective, especially in decreasing EBV-DNA, performs better than chemotherapy alone, and improves short-term survival rate. GPBSC infusion is suggested as a bridging treatment method to allo-HSCT.
\end{abstract}

Keywords: Hemophagocytic lymphohistiocytosis, Epstein-Barr virus, GPBSC infusion, Salvage therapy

\footnotetext{
* Correspondence: wangzhao@ccmu.edu.cn

Department of Hematology, Beijing Friendship Hospital, Capital Medical

University, YongAn Road 95th Xicheng District, Beijing 100050, China

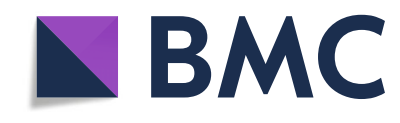

(c) The Author(s). 2020 Open Access This article is licensed under a Creative Commons Attribution 4.0 International License, which permits use, sharing, adaptation, distribution and reproduction in any medium or format, as long as you give appropriate credit to the original author(s) and the source, provide a link to the Creative Commons licence, and indicate if changes were made. The images or other third party material in this article are included in the article's Creative Commons licence, unless indicated otherwise in a credit line to the material. If material is not included in the article's Creative Commons licence and your intended use is not permitted by statutory regulation or exceeds the permitted use, you will need to obtain permission directly from the copyright holder. To view a copy of this licence, visit http://creativecommons.org/licenses/by/4.0/ The Creative Commons Public Domain Dedication waiver (http://creativecommons.org/publicdomain/zero/1.0/) applies to the data made available in this article, unless otherwise stated in a credit line to the data.
} 


\section{Background}

Hemophagocytic lymphohistiocytosis (HLH) is a severe or even fatal inflammatory state caused by a hereditary or acquired immunoregulatory abnormality, non-malignant proliferation of lymphocytes and tissue cells, and secretion of a large number of inflammatory cytokines [1]. HLH is divided into two categories: primary and acquired. Acquired HLH is often associated with and caused by infections, malignancies, and autoimmune diseases [2]. Among the infection-associated HLH, Epstein-Barr virus (EBV) infection-associated HLH (EBV-HLH) is one of the most common. In previous studies, EBV-HLH patients suffered a much worse prognosis than patients with other types of infection-associated HLH, especially in adult HLH patients [3-5]. In 2015, a study of 61 cases with EBV-HLH reported a 1-year overall survival (OS) of only $25.0 \%$ [6]. The current first-line treatment regimen, HLH94 followed by allo-HSCT fails to trigger a response under ideal conditions in $30 \%$ of children with all HLH triggers [7]. In a study of 133 adults and adolescents with EBV$\mathrm{HLH}$, the non-response rate of the HLH-94 regimen was $52 \%$ [5]. The DEP (doxorubicin-etoposide-methylprednisolone) regimen and L-DEP (PEG-asparaginase and DEP regimen combination) regimen, which is used as a salvage therapy for refractory EBV-HLH, achieve a much better overall response rate and increase the chance to receive allo-HSCT, which improves survival [8-10]. However, some patients still cannot proceed to the next allo-HSCT due to various factors, such as financial limitations, disease activity, and a lack of time to find a suitable donor. It has been reported that granulocyte colony-stimulating factor (G-CSF)-mobilized peripheral blood stem cell (GPBSC) infusion can mediate graft-versus-leukemia (GVL) effects and hasten hematologic recovery without amplifying graft-vs-host disease (GVHD) [11]. Additionally, many studies have shown that infusion of HLA-mismatched donor GPBSCs combined with chemotherapy increased CR rates, improved survival, and avoided GVHD in AML patients [12-15]. In this study, patients with refractory EBV-HLH and the inability to undergo allo-HSCT were treated with GPBSC infusion after chemotherapy. What is the effect of this treatment method on HLH? Can it contribute to hematologic recovery, EBV-DNA reduction, and prognosis improvement? Is it possible that GPBSC infusion can be a bridge to allo-HSCT for these patients? These issues are discussed in this retrospective study.

\section{Methods}

\section{Patients and donors}

The study was approved by the Ethics Committee at Beijing Friendship Hospital. Written informed consent was obtained from each patient and/or their family or guardian before the treatment began.
A retrospective case-control study of refractory EBV-HLH patients with GPBSC infusion from HLAmismatched donors after chemotherapy (GPBSC group) and sole chemotherapy (control group) was conducted. The patients in the control group were randomly selected from refractory EBV-HLH patients who underwent salvage therapy during the same period. Patients who were enrolled in this study fulfilled the following criteria: (1) patients satisfied HLH-2004 criteria at the time of initial diagnosis (the NK cell activity was tested by flow cytometry, ZL 201610013454.1) [1]; (2) high values for EBV-DNA copies in the peripheral blood $\left(>5.0 \times 10^{2}\right.$ copies $\left./ \mathrm{ml}\right)$ (tested with PCR assay); (3) primary HLH was excluded by HLH-related defective gene proteins PRF, GrB, XIAP, SAP, Munc13-4, Munc18-2, STX11, Rab27a, ITK, CD27, $\mathrm{AP} 3 \mathrm{~B} 1$, and whole genome sequencing if necessary, and lymphoma was excluded by repeated pathological biopsy of the focal area if there was an abnormal increase in FDG activity tested by positron emission tomography-computed tomography (PET-CT) and bone marrow biopsy; (4) treated with HLH-94 regimen (etoposide $150 \mathrm{mg} / \mathrm{m}^{2}$ twice weekly for 2 weeks and then weekly) and dexamethasone (initially $10 \mathrm{mg} / \mathrm{m}^{2}$ for 2 weeks followed by $5 \mathrm{mg} / \mathrm{m}^{2}$ for 2 weeks, $2.5 \mathrm{mg} / \mathrm{m}^{2}$ for 2 weeks, $1.25 \mathrm{mg} / \mathrm{m}^{2}$ for 1 week, and 1 week of tapering) [7] no less than 2 weeks before enrolment and did not achieve at least PR; and (5) patients are unable to perform allo-HSCT at that time point due to lack of donors, financial, patient and/or families' refusal, and hesitating or other reasons, such as economic limitation.

EBV infection was confirmed by identifying a significantly increased number of EBV-DNA copies in the peripheral blood. In the absence of the accepted diagnostic criteria, refractory HLH was defined according to previous research findings [16] and our clinical experience as failure to achieve at least PR according to an evaluation 2 weeks after receiving HLH-94 induction therapy.

Before GPBSC infusion, the HLA matching of donors and recipients was tested. The HLA matching of the GPBSC infusion group was HLA-mismatched with relative donors. All the donors were haplo-identical and at least $5 / 10$.

\section{Treatment methods}

Two kinds of treatment methods for patients: (1) GPBSC group: GPBSC infusion from HLA-mismatched donors after chemotherapy, in which the infusion of the cells was performed at $36 \mathrm{~h}$ after the chemotherapy regimen on day 0; (2) control group: treated only with chemotherapy. The chemotherapy regimen included salvage therapy: DEP regimen (liposomal doxorubicin $25 \mathrm{mg} / \mathrm{m}^{2}$ day 1 ; etoposide $100 \mathrm{mg} / \mathrm{m}^{2}$ was administered once on the first day of every week; methylprednisolone $15 \mathrm{mg} /$ $\mathrm{kg}$ days 1 to $3,2 \mathrm{mg} / \mathrm{kg}$ days 4 to $6,1 \mathrm{mg} / \mathrm{kg}$ days 7 to 10 , $0.75 \mathrm{mg} / \mathrm{kg}$ days 11 to $14,0.5 \mathrm{mg} / \mathrm{kg}$ days 15 to 21 , and 
$0.4 \mathrm{mg} / \mathrm{kg}$ days 22 to 28 ) and L-DEP regimen (PEGasparaginase $2000 \mathrm{U} / \mathrm{m}^{2}$ on day 5 ; liposomal doxorubicin (doxorubicin hydrochloride liposome injection) $25 \mathrm{mg} /$ $\mathrm{m}^{2} /$ day, day 1 ; etoposide $100 \mathrm{mg} / \mathrm{m}^{2} /$ day on the first day of every week; and methylprednisolone $15 \mathrm{mg} / \mathrm{kg} /$ day for days 1 to $3,0.75 \mathrm{mg} / \mathrm{kg} /$ day for days 4 to 7 , and $0.25 \mathrm{mg} /$ $\mathrm{kg} /$ day for days 8 to 10 ).

\section{Mobilization and apheresis of donor peripheral mononuclear cells}

Apheresis of HLA-mismatched donor peripheral mononuclear cells was carried out after the donor was subcutaneously injected with $5 \mu \mathrm{g} / \mathrm{kg} \mathrm{G}$-CSF twice a day for 5 days. Donor cells were divided into aliquots and were cryopreserved in liquid nitrogen, but freshly collected cells were used in the first course.

Detection of donor chimerism and donor microchimerism All patients in the GPBSC infusion group were assessed for donor chimerism after infusion. Eight patients were evaluated for donor microchimerism at least 1 week and 2 weeks after infusion.

\section{Evaluation criteria and observed indicators}

Efficacy was evaluated 2 and 4 weeks after initiating therapy according to the criteria proposed by Marsh et al. [16]. Complete response (CR) was defined as the normalization of all quantifiable symptoms and laboratory markers of $\mathrm{HLH}$, including the levels of soluble CD25, ferritin, and triglyceride; hemoglobin levels; neutrophil and platelet counts; and alanine aminotransferase (ALT) levels. Partial response (PR) was defined as improvement in two or more of the following quantifiable symptoms and laboratory markers by 2 weeks: 1.5 -fold decrease in soluble CD25 response; ferritin and triglyceride decreases of at least 25\%; an increase of at least $100 \%$ to $>0.5 \times 10^{9} / \mathrm{L}$ in patients with an initial neutrophil count of $<0.5 \times 10^{9} / \mathrm{L}$; an increase by at least $100 \%$ to $>2.0 \times 10^{9} / \mathrm{L}$ in patients with an initial neutrophil count of 0.5 to $2.0 \times 10^{9} / \mathrm{L}$; and a decrease of at least $50 \%$ in patients with initial ALT levels >400 U/L. Additionally, the subject's body temperature had to have reverted to normal ranges for either $C R$ or $P R$ to be diagnosed. Failure to achieve PR was defined as no response.

The observational indicators included symptoms and laboratory findings as indicated in the evaluation criteria. EBV-DNA copies in the peripheral blood were also observed.

\section{Survival time}

Survival times were calculated from the date of diagnosis of refractory EBV-HLH. All patients were followed-up until death or March 1, 2018, whichever occurred first.

\section{Statistical analysis}

SPSS 22.0 (IBM, USA) statistical software was adopted. Data that fit a normal distribution are presented as average \pm standard deviation, and those that did not are presented as median and range. $T$ test (two-sided) was used for data that fit a normal distribution and homogeneity of variance, and the Wilcoxon rank-sum test was used for others. Kaplan-Meier survival curves were used to analyze the patients' survival, and the log-rank test was used to evaluate survival time. $P<0.05$ was considered to denote a significant difference. Sample size calculation was performed using PASS 15 Power Analysis and Sample Size Software (2017, NCSS, LLC. Kaysville, Utah, USA) with $\beta=0.1$ and $\alpha=0.05$ (two independent proportions).

\section{Results}

\section{General conditions}

There were 18 cases of refractory EBV-HLH who accepted GPBSC infusion between March 2016 and Sep 2017 as the infusion group. The reasons these patients did not receive allo-HSCT at that time point were lack of donors $(n=3)$, financial considerations $(n=3)$, and patient and/or families' refusal $(n=5)$. The other 7 patients were hesitant about HSCT at that time point. In total, 19 patients were randomly selected from refractory EBV-HLH patients who underwent salvage therapy during the same period as the control group. The characteristics of the patients in the 2 groups are summarized in Table 1.

\section{Laboratory findings}

There was no difference in HLH features before treatment in the GPBSC infusion group and the control group (including WBC, HGB, PLT, TG, Fbg, Ferritin, AST, ALT, T-bil) $(p>0.05)$. After 2 weeks of treatment in the GPBSC group, some of the patients' laboratory indicators improved significantly, including WBC $(p=0.017)$, Fbg $(p=0.040)$, and ferritin $(p=0.039)$. The overall response rate was $66.7 \%(12 /$ $18)$, with a CR rate of $22.2 \%(4 / 18)$ and a PR rate of $44.4 \%$ $(8 / 18)$. However, there were no significant differences in WBC, HGB, PLT, TG, Fbg, Ferritin, AST, ALT, and T-bil between the two groups. Only the Fbg level was recovered better in the GPBSC infusion group $(p=0.003)$, indicating that the GPBSC group was similar to the chemotherapy alone group in terms of hematological recovery. The details are presented in Table 2.

In terms of EBV, there was no difference in EBV-DNA levels at diagnosis $\left(5.0 \times 10^{5}\left[1.5 \times 10^{3}, 7.7 \times 10^{7}\right]\right.$ vs. $1.0 \times$ $\left.10^{6}\left[2.0 \times 10^{3}, 5.2 \times 10^{7}\right], p=0.090\right)$ or before treatment $\left(1.1 \times 10^{5}\left[<5.0 \times 10^{2}, 3.0 \times 10^{6}\right]\right.$ vs. $5.7 \times 10^{5}\left[<5.0 \times 10^{2}\right.$, $\left.5.2 \times 10^{7}\right], p=0.951$ ) between the two groups. In the GPBSC group, EBV-DNA decreased significantly after 2 weeks $\left(5.0 \times 10^{3}\left[<5.0 \times 10^{2}, 5.7 \times 10^{5}\right], p=0.001\right)$ and 4 weeks $\left(4.1 \times 10^{3}\left[0,4.4 \times 10^{4}\right], p=0.012\right)$ after treatment, 
Table 1 Clinical features of patients in two groups before treatment

\begin{tabular}{llll}
\hline Clinical features & No. of patients & & $p$ valve \\
\cline { 2 - 3 } & Infusion group $(n=18)$ & Control group $(n=19)$ & $29[17-57]$ \\
Median age, years & $21[11-60]$ & $6: 13$ & 0.368 \\
Gender, female to male & $5: 13$ & $19(100 \%)$ & 0.800 \\
Fever & $18(100 \%)$ & $16(84.2 \%)$ & - \\
Splenomegaly/hepatomegaly & $16(88.9 \%)$ & $14(73.7 \%)$ & 0.677 \\
Hemophagocytosis & $14(77.8 \%)$ & $4(21.1 \%)$ & 0.772 \\
NK cell activity $<15.11 \%$ & $6(33.3 \%)$ & $19(100 \%)$ & 0.401 \\
soluble CD25 $>6400 \mathrm{pg} / \mathrm{ml}$ & $14(77.8 \%)$ & $1.0 \times 10^{6}\left[2.0 \times 10^{3}, 5.2 \times 10^{7}\right]$ & 0.100 \\
EBV-DNA (copies/ml) (at diagnosis) & $5.0 \times 10^{5}\left[1.5 \times 10^{3}, 7.7 \times 10^{7}\right]$ & & 0.090 \\
\hline
\end{tabular}

and the effect of the decrease was significantly better than that of the chemotherapy alone group in 2 weeks but not 4 weeks $\left(\mathrm{p}_{2 \mathrm{w}}=0.011, \mathrm{p}_{4 \mathrm{w}}=0.145\right)$ (Fig. 1$)$.

\section{Survival analysis}

The statistical analysis of the survival times ended on March 1, 2018. The overall mortality of the 34 patients was $75.7 \%(28 / 37)$, and the median survival time was 14.14 weeks [0.6-116.4]. A total of 13 of 18 in the GPBSC infusion group died (72.2\%); 7 of them died of HLH progression, 1 died of aGVHD after GPBSC infusion, 4 died of allo-HSCT-related causes, and 1 died of complications. The median survival time of the infusion group was 20.4 weeks [95\% CI 10.9, 29.9]. A total of 15 of 19 in the control group died (78.9\%); 8 of them died of HLH progression, 3 died of allo-HSCT-related causes, and 4 died of complications. The median survival time of the control group was 10.8 weeks [95\% CI 0-24.34116.4]. In the first 3 months after treatment, the GPBSC infusion group's survival was better than that of the control group (2-month survival $88.89 \%$ vs. $52.63 \%, p=$ 0.008 ; 3-month survival $83.33 \%$ vs. $47.09 \%, p=0.012$ ).
However, after 3 months, there was no difference between the two groups. In addition, there was no significant difference in overall survival (OS) between the two groups $(p=0.287)$ (Fig. 2).

\section{Graft-versus-host disease (GVHD)}

The median number of mononuclear cells (MNCs) infused was $7.60 \times 10^{8} / \mathrm{kg}$ (range, $5.1-12.2 \times 10^{8} / \mathrm{kg}$ ). The median infused CD34+ cell number was $2.355 \times 10^{6} / \mathrm{kg}$ (range, $1.17-4.924 \times 10^{6} / \mathrm{kg}$ ). The number of infused cells was mainly to ensure that the infusion was effective. At present, there are no standard recommendations on the doses of infused cells for GPBSC infusion therapy. The doses of CD34 + cells infused in this study were with reference to the doses of cells (CD34+ $1.7 \times 10^{6} / \mathrm{kg}$, range, $1.1-4.6) \times 10^{6} / \mathrm{kg}$ ) infused in the study of Mei Guo et al. [13]. Among the 18 patients who underwent GPBSC infusion, 7 (38.9\%) had acute GVHD (aGVHD) signs, 5 of which had liver dysfunction and gastrointestinal symptoms, and the other 2 cases had liver dysfunction or gastrointestinal symptoms. However, 6 of them improved after symptom-specific treatment. Only 1 patient experienced

Table 2 Comparison between two treating groups

\begin{tabular}{|c|c|c|c|c|c|c|}
\hline & \multicolumn{2}{|l|}{ Before } & \multirow{2}{*}{$\begin{array}{l}P \\
\text { value }\end{array}$} & \multicolumn{2}{|l|}{2 weeks } & \multirow[t]{2}{*}{$p$ value } \\
\hline & GPBSCS & control & & GPBSCS & control & \\
\hline WBC & $1.36[0.2,2.4]$ & $1.8[0.5,7.4]$ & 0.134 & $2.68[0.17,15.38]$ & $3.95[0.2,12]$ & 0.696 \\
\hline $\mathrm{HGB}$ & $81.5 \pm 17.701$ & $94.63 \pm 27.132$ & 0.092 & $82.75 \pm 18.614$ & $97.19 \pm 17.608$ & 0.032 \\
\hline PLT & $49.5[12,340]$ & $45[3,499]$ & 0.893 & $47[3,313]$ & $88[26,451]$ & 0.102 \\
\hline TG & $2.59[0.6,12.78]$ & $2.05[1.39,5.29]$ & 0.929 & $1.89[1.02,8.86]$ & $1.63[0.74,4.11]$ & 0.093 \\
\hline Fbg & $1.04[0.84,2.91]$ & $1.045[0.3,2.12]$ & 0.252 & $2.16[0.77,4.24]$ & $1.065[0.53,2.74]$ & 0.003 \\
\hline Ferritin & $3843.1[28,24,174]$ & $3207[118,455,000]$ & 0.909 & $3352.5[255,40,699]$ & $1433[16,7549]$ & 0.068 \\
\hline AST & $52.5[13.3,229.9]$ & $65[26,766]$ & 0.150 & $35.7[12.8,181]$ & $28[8,680.2]$ & 0.261 \\
\hline ALT & $58[14,252]$ & $76[10,310]$ & 0.425 & $59[6,502]$ & $34.5[4,227]$ & 0.123 \\
\hline T-bil & $18.725[8.01,85.66]$ & $50.925[7.48,289.66]$ & 0.088 & $33.51[9.36,169.14]$ & $17.34[1.84,192.69]$ & 0.551 \\
\hline $\begin{array}{l}\text { EBV- } \\
\text { DNA }\end{array}$ & $\begin{array}{l}1.1 \times 10^{5}\left[<5.0 \times 10^{2}, 3.0 \times\right. \\
\left.10^{6}\right]\end{array}$ & $\begin{array}{l}5.7 \times 10^{5}\left[<5.0 \times 10^{2}, 5.2 \times\right. \\
\left.10^{7}\right]\end{array}$ & 0.304 & $\begin{array}{l}5.0 \times 10^{3}\left[<5.0 \times 10^{2}, 5.7 \times\right. \\
\left.10^{5}\right]\end{array}$ & $\begin{array}{l}6.6 \times 10^{4}\left[<5.0 \times 10^{2}, 9.0 \times\right. \\
\left.10^{7}\right]\end{array}$ & 0.011 \\
\hline ECOG & 2.78 & 2.63 & 0.606 & 2.56 & 2.42 & 0.645 \\
\hline
\end{tabular}




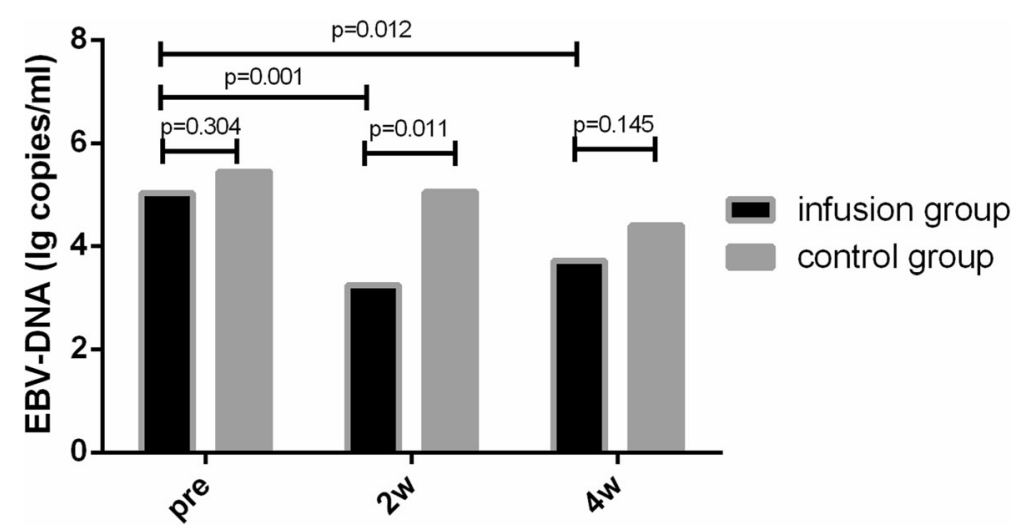

Fig. 1 EBV-DNA before, 2 weeks and 4 weeks after treatment between two groups. There was no difference in EBV-DNA levels before treatment $(p=0.304)$ between two groups. In the GPBSC group, EBV-DNA decreased significantly after 2 weeks $(p=0.001)$ and 4 weeks $(p=0.012)$ after treatment, and the effect of the decrease was significantly better than that of the chemotherapy alone group in 2 weeks but not 4 weeks $(p 2 w=0.011, p 4 w=0.145)$

sustained and eventually died of aGVHD. The details of graft and GVHD are presented in Table 3.

\section{Donor chimerism and donor microchimerism}

Only one patient in the GPBSC group developed mixed chimerism, and the highest peripheral chimerism rate was $93.45 \%$ (3 weeks after treatment). This patient eventually died of aGVHD. In the other 10 patients who underwent microchimerism detection, micro-chimerism was detected $(0.008-3.26 \%)$. In 2 weeks after treatment, microchimerism was detected in $8 / 8$. There were 3 patients whose microchimerism was also detected again at 3 weeks (Table 3 ).

\section{Discussion}

EBV-HLH suffers a poorer prognosis than other subtypes of secondary HLH, especially relapsed and refractory EBVHLH [17, 18]. Without effective treatment, short-term mortality is high, and most patients with relapsed EBHHLH die within the first few weeks [7]. Allogeneic hematopoietic stem cell transplantation (allo-HSCT) is often required for EBV-HLH, especially for adults and refractory/relapsed patients. It is thought that allo-HSCT can induce immune reconstitution, thus enabling patients to effectively eliminate EB virus $[3,19]$. In one Japanese cohort, allo-HSCT resulted in an 85.7\% 10-year OS for patients with EBV-HLH [20]. In a retrospective analysis from our center, $27.1 \%$ of patients with EBV-HLH received allo-HSCT, and the final survival rate was 52.78\% [5]. However, some patients in the actual situation are unable to receive allo-HCST due to various factors. It has been reported that granulocyte colony-stimulating factor (G-CSF)mobilized peripheral blood stem cell (GPBSCs) infusion can mediate GVL effects and hasten hematologic recovery without amplifying GVHD in AML [11]. Considering the important position of allo-HSCT, we tried to use GPBSC infusion as a salvage treatment in patients with refractory EBV-HLH. This study found that for patients with refractory EBV-HLH, GPBSC infusion therapy could more effectively reduce EBV-DNA levels after 2 and 4 weeks but

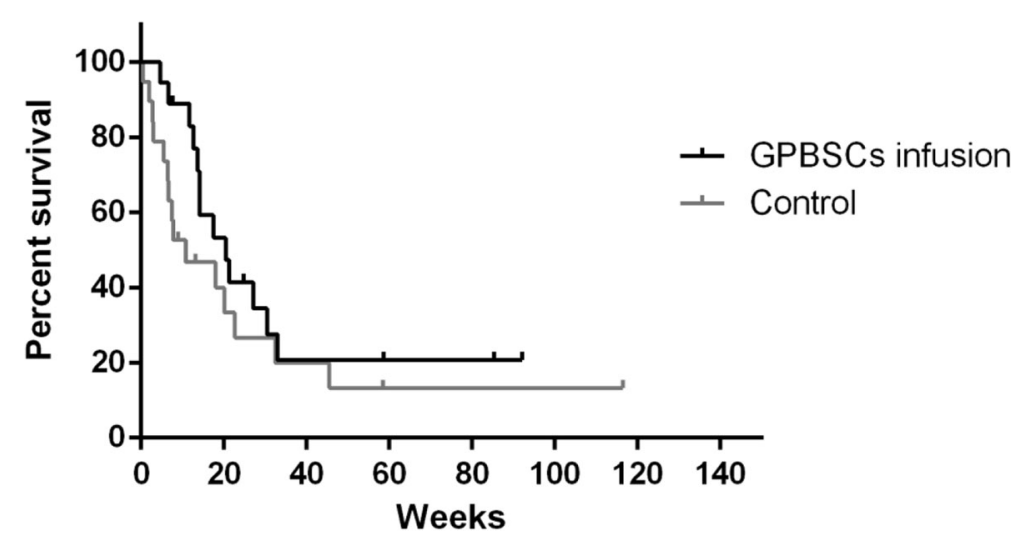

Fig. 2 Overall survival (OS) between two groups $(p=0.259)$ 
Table 3 Graft details and donor microchimerism rate after GPBSC infusion

\begin{tabular}{|c|c|c|c|c|c|c|c|c|}
\hline \multirow[t]{2}{*}{ Patient } & \multicolumn{2}{|l|}{ Graft } & \multicolumn{4}{|c|}{ Donor microchimerism rate (\%) } & \multicolumn{2}{|l|}{$\mathrm{aGVHD}$} \\
\hline & $\begin{array}{l}\text { Mononuclear } \\
\text { (cells/kg) }\end{array}$ & CD34+ (cells/kg) & 1 week & 2 weeks & 3 weeks & 4 weeks & Organ system affected & $\begin{array}{l}\text { Severity } \\
\text { scoring }\end{array}$ \\
\hline 1 & 12.2 & 4.56 & 37.4 & 86.0 & 93.89 & & $\begin{array}{l}\text { Elevated LFTs, rash, } \\
\text { Gl symptoms }\end{array}$ & IV \\
\hline 2 & 5.5 & 2.31 & 0.024 & 0.081 & & & & \\
\hline 3 & 9.7 & 2.115 & 0.023 & 0.014 & 0.005 & & & \\
\hline 4 & 5.5 & 2.59 & - & & & & & \\
\hline 5 & 5.1 & 1.17 & 0.846 & 0.148 & & & $\begin{array}{l}\text { Elevated LFTs, } \\
\text { Gl symptoms }\end{array}$ & $\|$ \\
\hline 6 & 5.2 & 2.08 & 0.17 & & & & $\begin{array}{l}\text { Elevated LFTs, } \\
\text { Gl symptoms }\end{array}$ & $\|$ \\
\hline 7 & 6.4 & 1.4 & - & & & & & \\
\hline 8 & 11.6 & 2.43 & 0.15 & 0.25 & & & & \\
\hline 9 & 10.1 & 2.4 & - & & & & Gl symptoms & I \\
\hline 10 & 9.7 & 4.924 & 11.21 & 0.15 & 0.01 & 0.01 & $\begin{array}{l}\text { Elevated LFTs, } \\
\text { Gl symptoms }\end{array}$ & $\|$ \\
\hline 11 & 16.4 & 3.19 & - & & & & & \\
\hline 12 & 5.3 & 1.325 & 0.002 & 0.001 & & & Elevated LFTs & I \\
\hline 13 & 9.6 & 3.11 & 0.008 & & & & & \\
\hline 14 & 6.1 & 2.04 & - & & & & & \\
\hline 15 & 8.8 & 2.65 & - & & & & & \\
\hline 16 & 16.5 & 2.31 & 0.37 & 0.31 & 0.034 & & & \\
\hline 17 & 5.1 & 2.448 & - & & & & & \\
\hline 18 & 5.7 & 1.824 & 3.26 & 0.76 & & & Elevated LFTs, Gl & $\|$ \\
\hline
\end{tabular}

LFT liver function test, Gl gastrointestinal

had no significant effect on the recovery of blood parameters. The 3-month survival was improved, but there was no significant effect on overall survival.

The G\PBSC infusion therapy in the treatment of leukemia reported in previous literature can significantly shorten the recovery time of white blood cells and platelets [11]. GPBSCs is a stimulated cell infusion. The current speculation is that, in contrast to unstimulated DLI, the larger numbers of lymphocytes, CD34 cells, natural killer (NK) cells, and cytokines, contained in G-PBSCs, may contribute roles in promoting hematopoietic recovery [13, 21]. However, in this study, there was no significant difference in the recovery of blood parameters in the GPBSC infusion group compared with the uninfused group, although similar levels of donor chimerism were observed in this study, which was consistent with the previous study of leukemia. It is possible that the disease state of HLH is different from that of leukemia. The decline in blood cells in HLH is mainly related to the production and action of a large number of inflammatory mediators [19]. This is different from the bone marrow suppression caused by chemotherapy drugs in the treatment of leukemia. HLH needs to be controlled by controlling inflammatory cells and then controlling the inflammatory factor storm [22]. However, the mechanism of hematopoietic recovery of GPBSCs is still unclear, especially in the context HLH, and the specific internal mechanism still needs further study.

Interestingly, GPBSC infusion after chemotherapy was more effective at reducing EBV-DNA viral load than regular chemotherapy. This may be similar to the GVL effect of GPBSCs in the treatment of leukemia: the lymphocytes of the infused donor cells act synergistically with the recipient's immune system to delete EBVinfected cells, thereby reducing Epstein-Barr virus load. However, prior studies suggested that the main mediator of GVL in leukemia is NK cells, and other cells, such as $\mathrm{T}$ cells, mainly function in GVL by interacting with the recipient's immune system $[13,23]$. However, in HLH, $E B$ virus clearance mainly relies on $E B$ virus-specific CD8 + T cells [24]. Previous studies have found that EBV-specific CD8+ $\mathrm{T}$ recombination occurs in the early phase of allo-PBSCT; even if the total number of $\mathrm{T}$ cells decreased, the proportion of $\mathrm{CD} 8+\mathrm{T}$ is still elevated, but this phenomenon was not observed in cord blood transplantation [25]. The GVL effect of DLI is mainly through donor chimerism or mixed chimerism [23]. In this study, only one patient achieved mixed chimerism after the infusion of cells, although the number of cells 
infused was not different from those of other patients. This patient eventually died of GVHD, but the EBV viral load of this patient decreased significantly, and EBVDNA turned negative after 4 weeks, suggesting that the effect of the reduction of EBV-DNA is achieved by the GVL-like effect of lymphocytes in the infused cells, similar to that observed in leukemia. With the patients who were tested for chimerism in this study, all of them had microchimerism except the patient mentioned above. Almost all patients with microchimerism did not develop mixed chimerism, suggesting that donor or mixed chimerism is difficult to achieve with GPBSC infusion. However, with the persistence of micro-chimerism, a small number of donor cells persist in the patient; this micro-chimerism may be the main reason by which GPBSCs effectively reduce the EBV-DNA level. Due to the small sample size of this study, no correlation between the micro-chimerism rate and the decline in EBV-DNA levels was found. However, in the previous microtransplant study, the micro-chimerism rate reached a peak at 7-14 days after infusion [11]. This is consistent with the efficacy of EBV-DNA's reduction, which was maximal in 2 weeks, but more data are needed to validate the relationship. However, the efficacy of EBV-DNA reduction cannot persist; as in 4 weeks after treatment, there is no difference in EBV-DNA level between the 2 groups. We speculate that the loss of differences in EBV viral load is related to possible depletion of GPBSCs. Considering the transient efficacy of GPBSC infusion, allo-HSCT should be taken into consideration as soon as HLH is controlled. Therefore, GPBSC infusion may play a role in bridging the alloHSCT, especially for those patients who have not had a previous transplant opportunity.

Except for the one patient mentioned above, who achieved mixed chimerism and suffered severe GVHD causing death, only 6 of the remaining 14 patients developed aGVHD signs, and all of them improved rapidly after symptomatic treatment, even if the number of CD3+ cells infused was high. None of the 15 patients in the GPBSC infusion group underwent GVHD prevention treatment. Regardless of DLI or haploid transplantation, although the GVL effect is very impressive, the GVHD is also very severe [26]. Although GPBSC infusion is a kind of transplantation with infused donor cells and chemotherapy, it was not used as a pretreatment regimen with strong immunosuppressive effects similar to haploid transplantation [11]. No severe immunosuppression significantly reduces the incidence and severity of GVHD after infusion. However, considering that one patient died of severe GVHD in this study, more considerations are required for special circumstances, and close monitoring of GVHD after the infusion is still necessary.

In terms of survival, the survival rate of the GPBSC infusion group was better than that of the control group within 3 months, but there was no significant difference in the long-term survival. This may suggest that GPBSC infusion can help with refractory EBV-HLH, but only provides effects in the short term. Allo-HSCT is still needed to achieve long-term remission [27]. Therefore, we suggest using GPBSCs as a bridging treatment method to allo-HSCT for those refractory EBV-HLH patients who did not have a previous opportunity for allo-HSCT.

\section{Conclusion}

Infusing HLA-mismatched donor GPBSCs combined with chemotherapy is effective in refractory EBV-HLH. It can decrease EBV-DNA levels in 2 and 4 weeks, and it performs better than chemotherapy alone in 2 weeks. Infusing HLA-mismatched donor GPBSCs combined with chemotherapy can also improve the short-term survival rate. This effect is similar to the effect of GVL in leukemia, but it is not exactly the same, which is probably due to the GVL-like effect of lymphocytes in the infused cells, and microchimerism may be important. However, the effects are short-term. After the exhaustion of donor cells, alloHSCT is still needed. GPBSC infusion is suggested as a bridging treatment method to allo-HSCT for those refractory EBV-HLH patients who have not had a previous opportunity for transplantation.

\begin{abstract}
Abbreviations
Allo-HSCT: Allogeneic hematopoietic stem cell transplantation; ALT: Alanine aminotransferase; CR: Complete response; DEP regimen: Doxorubicin hydrochloride liposome, etoposide, and methylprednisolone; EBER: EBVencoded small RNA; EBV: Epstein-Barr virus; GVHD: Graft versus host disease; HLH: Hemophagocytic lymphohistiocytosis; L-DEP regimen: PEG-aspargase plus DEP regimen; NK: Natural killer; OS: Overall survival; PR: Partial response; VP-16: Etoposide; GPBSCs: Granulocyte colony-stimulating factor-mobilized peripheral blood stem cells
\end{abstract}

\section{Acknowledgements}

We thank the patients and their families for participating in our study.

\section{Authors' contributions}

ZW contributed to the design of the study. YNW and JSW helped with the study design and data analyses. YS conducted the data analysis and wrote the manuscript. The authors approved the final manuscript.

\section{Funding \\ This work was supported by the National Natural Science Foundation of China (No.81871633), Beijing Natural Science Foundation (No.7181003), Beijing Municipal Administration of Hospitals Clinical Medicine Development of Special Funding (ZYLX201702), Beijing Municipal Administration of Hospitals' Ascent Plan (DFL20180101), Beijing Municipal Administration of Hospitals Incubating Program (PX2018003), Beijing Municipal Administration of Hospitals' Youth Program (QML20160102), and Beijing Municipal Administration of Hospitals Clinical Technology Innovation Project (XMLX201803).}

\section{Availability of data and materials}

The datasets used during the current study are available from the corresponding author on request. 


\section{Ethics approval and consent to participate}

The study was approved by the Ethics Committee at Beijing Friendship Hospital. Written informed consent was obtained from each patient and their family or guardian before the treatment began.

\section{Consent for publication}

We have obtained consent to publish from the participants and/or their families or guardian.

\section{Competing interests}

The authors declare that they have no competing interests.

Received: 2 February 2020 Revised: 24 May 2020

Accepted: 18 June 2020 Published online: 01 July 2020

\section{References}

1. Henter Jl, Horne A, Arico M, et al. HLH-2004: diagnostic and therapeutic guidelines for hemophagocytic lymphohistiocytosis. Pediatr Blood Cancer. 2007:48:124-31.

2. Maakaroun NR, Moanna A, Jacob JT, Albrecht H. Viral infections associated with haemophagocytic syndrome. Rev Med Virol. 2010;20:93-105.

3. Imashuku S. Treatment of Epstein-Barr virus-related hemophagocytic lymphohistiocytosis (EBV-HLH); update 2010. J Pediatr Hematol Oncol. 2011; 33:35-9.

4. Merrill SA, Naik R, Streiff MB, et al. A prospective quality improvement initiative in adult hemophagocytic lymphohistiocytosis to improve testing and a framework to facilitate trigger identification and mitigate hemorrhage from retrospective analysis. Medicine (Baltimore). 2018;97:e11579.

5. Lai W, Wang Y, Wang J, Wu L, Jin Z, Wang Z. Epstein-Barr virus-associated hemophagocytic lymphohistiocytosis in adults and adolescents - a lifethreatening disease: analysis of 133 cases from a single center. Hematology. 2018;23:810-6

6. Zeng $X$, Wei N, Wang Y, et al. Treatment outcomes and prognostic analysis of 61 Epstein-Barr virus-associated hemophagocytic lymphohistiocytosis. Zhonghua Xue Ye Xue Za Zhi. 2015;36:507-10.

7. Henter Jl, Samuelsson-Horne A, Arico M, et al. Treatment of hemophagocytic lymphohistiocytosis with HLH-94 immunochemotherapy and bone marrow transplantation. Blood. 2002;100:2367-73.

8. Wang YHW, Hu L, Cen X, Li L, Wang J. Multicenter study of combination DEP regimen as a salvage therapy for adult refractory hemophagocytic lymphohistiocytosis. Blood. 2015;126(19):2186-92.

9. Wang J, Wang Y, Wu L, Zhang J, Lai W, Wang Z. PEG-aspargase and DEP regimen combination therapy for refractory Epstein-Barr virus-associated hemophagocytic lymphohistiocytosis. J Hematol Oncol. 2016;9:84.

10. Li Z, Wang Y, Wang J, Zhang J, Wang Z. Haploidentical hematopoietic stem cell transplantation for adult patients with Epstein-Barr virus-associated hemophagocytic lymphohistiocytosis. Leuk Lymphoma. 2018:59:77-84.

11. Guo M, Hu KX, Liu GX, et al. HLA-mismatched stem-cell microtransplantation as postremission therapy for acute myeloid leukemia: long-term follow-up. J Clin Oncol. 2012;30:4084-90.

12. Guo M, Chao NJ, Li JY, et al. HLA-mismatched microtransplant in older patients newly diagnosed with acute myeloid leukemia: results from the microtransplantation interest group. JAMA Oncol. 2018;4:54-62.

13. Guo M, Hu KX, Yu CL, et al. Infusion of HLA-mismatched peripheral blood stem cells improves the outcome of chemotherapy for acute myeloid leukemia in elderly patients. Blood. 2011;117:936-41.

14. Li WY, Wang Y, Chen SN, et al. Consolidation therapy with decitabine and intermediate-dose cytarabine followed by HLA-mismatched peripheral blood stem cells infusion for older patients with acute myeloid leukemia in first remission. Leuk Lymphoma. 2018;59:1652-8.

15. Yuan L, Sun L, Yang L, Jing $Y$. Acute graft-versus-host disease in a nonhematopoietic stem cell transplantation candidate treated with decitabine followed by granulocyte colony-stimulating factor-primed peripheral blood stem cells infusion: a special entity of the disease? Transfusion. 2014:54:190-3.

16. Marsh RA, Allen CE, McClain KL, et al. Salvage therapy of refractory hemophagocytic lymphohistiocytosis with alemtuzumab. Pediatr Blood Cancer. 2013;60:101-9.

17. Tseng YT, Sheng WH, Lin BH, et al. Causes, clinical symptoms, and outcomes of infectious diseases associated with hemophagocytic
Iymphohistiocytosis in Taiwanese adults. J Microbiol Immunol Infect. 2011; 44:191-7.

18. Yanagisawa R, Nakazawa $Y$, Matsuda $K$, et al. Outcomes in children with hemophagocytic lymphohistiocytosis treated using $\mathrm{HLH}-2004$ protocol in Japan. Int J Hematol. 2019;109:206-13.

19. Janka GE, Lehmberg K. Hemophagocytic lymphohistiocytosis: pathogenesis and treatment. Hematol Am Soc Hematol Educ Program. 2013;2013:605-11.

20. Ohga $\mathrm{S}$, Kudo $\mathrm{K}$, Ishii $\mathrm{E}$, et al. Hematopoietic stem cell transplantation for familial hemophagocytic lymphohistiocytosis and Epstein-Barr virusassociated hemophagocytic lymphohistiocytosis in Japan. Pediatr Blood Cancer. 2010:54:299-306.

21. Orti G, Barba P, Fox L, Salamero O, Bosch F, Valcarcel D. Donor lymphocyte infusions in AML and MDS: enhancing the graft-versus-leukemia effect. Exp Hematol. 2017:48:1-11.

22. Wang Y, Wang Z. Treatment of hemophagocytic lymphohistiocytosis. Curr Opin Hematol. 2017;24:54-8

23. Haines HL, Bleesing JJ, Davies SM, et al. Outcomes of donor lymphocyte infusion for treatment of mixed donor chimerism after a reduced-intensity preparative regimen for pediatric patients with nonmalignant diseases. Biol Blood Marrow Transplant. 2015;21:288-92.

24. Smith MC, Cohen DN, Greig B, et al. The ambiguous boundary between EBV-related hemophagocytic lymphohistiocytosis and systemic EBV-driven T cell lymphoproliferative disorder. Int I Clin Exp Pathol. 2014;7:5738-49.

25. Marshall NA, Howe JG, Formica R, et al. Rapid reconstitution of Epstein-Barr virus-specific T lymphocytes following allogeneic stem cell transplantation. Blood. 2000:96:2814-21.

26. Scarisbrick JJ, Dignan FL, Tulpule S, et al. A multicentre UK study of GVHD following DLI: rates of GVHD are high but mortality from GVHD is infrequent. Bone Marrow Transplant. 2015;50:62-7.

27. Kogawa K, Sato H, Asano T, et al. Prognostic factors of Epstein-Barr virusassociated hemophagocytic lymphohistiocytosis in children: report of the Japan Histiocytosis Study Group. Pediatr Blood Cancer. 2014;61:1257-62.

\section{Publisher's Note}

Springer Nature remains neutral with regard to jurisdictional claims in published maps and institutional affiliations.

Ready to submit your research? Choose BMC and benefit from:

- fast, convenient online submission

- thorough peer review by experienced researchers in your field

- rapid publication on acceptance

- support for research data, including large and complex data types

- gold Open Access which fosters wider collaboration and increased citations

- maximum visibility for your research: over $100 \mathrm{M}$ website views per year

At $\mathrm{BMC}$, research is always in progress.

Learn more biomedcentral.com/submissions 